\title{
Robotics in Education
}

\author{
Belén Curto • Vidal Moreno
}

Published online: 28 November 2015

(C) Springer Science+Business Media Dordrecht 2015

Robotics in Education (R-in-E) tries to strengthen the learning skills of future engineers and scientists by means of robot-based projects. Both in school and in college, presenting robots in the classroom will give students a more interesting (and fun) vision of science and engineering, and they will be able to observe directly the practical application of theoretical concepts in the fields of mathematics and technology. $\mathrm{R}$-in-E is inclusive in nature, which can lead students to orient their university studies in fields related to the STEM subjects. From the point of view of University, robot-based projects put together, since their inception, key competences related to mechatronics. This will help students deepen their knowledge, and it will also help engineers and scientists of the $21^{\text {st }}$ century to finish their studies.

One could also point out that R-in-E furthers and strengthens both in curricular and in extracurricular activities values such as creativity, innovation, support, cooperation and teamwork. Clearly, these values must be promoted in our society.

"R-in-E" puts together actors from disparate ecosystems: on the one hand, experts and researchers in education, teachers and professors, cultural entertainers in public and private institutions, and on the

B. Curto $(\varangle) \cdot$ V. Moreno

Departamento Informática y Automática,

Facultad de Ciencias, Universidad de Salamanca,

Plaza de la Merced S/N, 37008 Salamanca, Spain

e-mail: bcurto@usal.es other hand, robot companies and material providers, researchers from public and private centers and spinoffs; experts in mechatronics and robotics. The goal of this special issue is to present contributions related to the latest advances in "R-in-E" which come from both ecosystems.

Submitted contributions were reviewed by two international experts in the field; after two iterations of the revision process, ten articles were selected to be included in this special issue.

The main topics addressed by these papers are: printable robots, web-based materials, simulation tools, laboratory experiments, experiences with new teaching materials in R-in-E, among others.

L. Armesto et al. explain how low-cost printable robots (printbots) could be incorporated directly in university engineering subjects as powerful educational tools. Authors describe real experiences that have been carried out during a decade of regular teaching, and especially within a study program called European Project Semester, which is based on Project Organized Learning. Multidisciplinary and multicultural student teams develop a project from the original idea to the commercialization of the product (a printbot), thus showing the excellent pedagogical results one obtains.

R. Pérula et al propose an educative robotic platform based on low-cost Open Source technologies, which is an easily replicable/printable mobile mini-robot. Mechanical parts, controllers, sensors and actuators are explained exhaustively, as well as 
programming tools. The evaluation of activities carried out in various sceneries with remarkable success in terms of assistance, show how Robotics promotes creativity for beginner university students with no previous knowledge in robotics.

Hak Yi et al. present experiential learning in the development of a miniature-sized educational humanoid robot, called DARwIn-HP, carried out by self-directed undergraduate students. Authors claim that this hands-on experience has a double beneficial effect on students. In their engineering curriculum, it allows them to understand the fundamental materials of humanoid robots in theory as well as the usage of mechanical tools in practice. In their personal development, it motivates them in order to participate in outreach and extracurricular activities, which increases voluntary work.

A. El-Fakdi and X. Cufi highlight the efforts carried out by the Computer Vision and Robotics Group to promote engineering programs among secondary school students. Within a project-based activity, build their own robot: a ROV (Remotely Operated Vehicle). During the last six years, 352 students have participated in workshops organized by the Group, and the total number of ROVs built is 80 .

F. M. López and F. Cuesta describe the design of an educational Internet connected low-cost open mobile robot, with various sensors and communication resources. Their policy is of the type "BYOD: Bring your own devices", and they program robots with their own smartphones. This was a very surprising and attractive educational task for students in a vocational education school.

E. Cervera et al. present an initiative called Robot Programming Network (RPN), which tries to create a network of robotics education laboratories with remote programming capabilities. It consists both of online open course materials and of online servers that are ready to execute and test the programs written by remote students. In order to test the RPN platform, a pilot study was carried out by students from engineering degrees (electrical, mechanical, chemistry), with none or little previous experience in programming.
$88 \%$ of the students believed that the learning experience was better or much better than traditional methods.

D. Zapata et al propose a series of activities focused on learning automation and robotics, and based on the use of an aerial robotic system. These activities are designed following the project-based learning methodology. Authors claim they facilitate the achievement of learning objectives included in national and international standards for engineering education, according to what their results show.

A. Alvarez and M. Larrañaga analyse experiences obtained by incorporating robots in a course on Basic Programming within a degree in Computer Engineering. Authors propose a classification of objectives (O-Motivation, O-Improvement and O-Perception) for the analysis of experiences by means of an interview of students, grades obtained and the opinion of teachers. Results concerning the first and third objectives were satisfactory, but not the second one, related to final grades of students.

E. Fabregas et al. describe the components of a pedagogical tool to simulate the management of the formation of a group of robots. Moreover, it allows the experimentation on actual robots using several low-cost Moway robots. The authors claim that the platform constitutes a ready-to-use test tool that provides to engineering master students the opportunity to simulate and test many different formation and cooperation control strategies.

A. Peidró and al present a virtual and remote laboratory of parallel robots consisting of a simulation tool and a real robot, both of them developed by the authors. The virtual tool developed helps students to simulate the inverse and forward kinematic problems of three parallel robots in an intuitive and graphical way. On the remote lab, the students can experiment with a real parallel robot and let them explore phenomena that arise in the motion of the real robot and do not happen in simulation.

Finally, we would like to thank all researchers having submitted papers to this special issue and we hope to see many of these contributions published in future issues. 